\title{
An Experimental and Numerical Study of N-Dodecane/Butanol Blends for Compression Ignition Engines
}

\author{
Anil Bhaurao Wakale \\ Indian Institute of Technology \\ Samah Y. Mohamed, Nimal Naser, and Mohammed Jaasim Mubarak ali \\ King Abdullah University of Science and Technology \\ Raja Banerjee \\ Indian Institute of Technology \\ Hong Im and S.Mani Sarathy \\ King Abdullah University of Science and Technology
}

\begin{abstract}
Alcohols are potential blending agents for diesel that can be effectively used in compression ignition engines. This work investigates the use of $\mathrm{n}$-butanol as a blending component for diesel fuel using experiments and simulations. Dodecane was selected as a surrogate for diesel fuel and various concentrations of n-butanol were added to study ignition characteristics. Ignition delay times for different n-butanol/dodecane blends were measured using the ignition quality tester at KAUST (KR-IQT). The experiments were conducted at pressure of 21 and 18 bar, temperature ranging from $703-843 \mathrm{~K}$ and global equivalence ratio of 0.85 . A skeletal mechanism for $n$ dodecane and n-butanol blends with 203 species was developed for numerical simulations. The mechanism was developed by combining n-dodecane skeletal mechanism containing 106 species and a detailed mechanism for all the butanol isomers. The new mixture mechanism was validated for various pressure, temperature and equivalence ratio using a 0-D homogeneous reactor model from CHEMKIN for pure base fuels (n-dodecane and butanol). Computational fluid dynamics (CFD) code, CONVERGE was used to further validate the new mechanism. The new mechanism was able to reproduce the experimental results from IQT at different pressure and temperature conditions.
\end{abstract}

\section{Introduction}

Biofuels like bio-alcohols are being actively investigated as alternatives to petroleum-based hydrocarbon fuels to reduce dependence on such fossil fuels and more importantly to reduce tail pipe emissions. The presence of extra oxygen in such alternative fuels plays an important role in reducing engine-out emissions, especially $\mathrm{NOx}$ and soot production during combustion process. In India, according to Government of India's (GOI) National Policy of Bio-Fuels [1], 20\% (by vol.) blending of bio-fuels needs to be achieved both for bio-diesel and bio-ethanol. For diesel applications, this reportedly led to the reductions of $7.35,9.25,13.61,20$, and $13 \%$ in $\mathrm{HC}, \mathrm{CO}, \mathrm{PM}, \mathrm{NOx}$ and polycyclic aromatic hydrocarbons (PAH), respectively [2]

Though bio-alcohols like ethanol and methanol were initially blended with diesel, butanol is now deemed to be a promising alternative for $\mathrm{CI}$ engine as its properties like density, viscosity and surface tension are close to diesel fuels and can mix well with diesel in all proportions. Sarathy et al [3] have reviewed combustion chemistry of

Page 1 of 8 alcohol and their application to engine relevant applications. Methanol and ethanol have high water absorption properties and surfactants are required to blend them with diesel due to their poor miscibility with diesel. The calorific value of butanol is higher than ethanol or methanol and can be used in currently available engines without any modification [4-5]

Jin and co-workers [6] studied the use of butanol as an alternative biofuel for internal combustion engines. They compared the properties of butanol with conventional gasoline, diesel fuel and some other alcohols like methanol, ethanol and biodiesel. Rakopoulos et al [7-8] investigated the effect of butanol in conventional diesel engine $(0-24 \%$ by vol.) on performance and exhaust emissions of heavy duty and high speed diesel engines. It was found that diesel/butanol blends show higher specific fuel consumption and slight increase in brake thermal efficiency. Furthermore, when the exhaust temperature was reduced, significant decrease in smoke and marginal decrease in NOx was observed because of excess oxygen content in butanol.

Dogan et al. [9] and Al-Hasan et al. [10] reported that butanol blending in diesel engines reduces soot and NOx. Multiple injection strategy (pilot and post injection) with different butanol composition shows similar emissions levels as pure diesel up to $15 \%$ blending by vol. With an addition of butanol in diesel fuel, it was found that butanol leads to enhanced premixed combustion, resulting in increased first stage heat release. Higher amount of exhaust gas recirculation (EGR) can be used with butanol blending without affecting total hydrocarbons (THC), $\mathrm{CO}$ and soot emissions [11]. Dhinesh et al $[12,13]$ studied the effect of Cymbopogon flexuosus biofuel (CFB) blends on performance, emission and combustion with single cylinder diesel engine. The studied shows with $20 \%$ blend of CFB lowers the hydrocarbon, $\mathrm{CO}$ and smoke emissions because of availability of oxygen atom in CFB. Thus the above all study shows butanol can be used safely and advantageously with diesel fuel in compression ignition engine.

Engine CFD simulations is now being actively used to predict incylinder combustion dynamics [14-18]. These engine simulations reproduce details of engine spray, in-cylinder aerodynamics and the combustion dynamics [19], thus providing new insights for further development and optimization of engines. The physical and chemical processes in diesel combustion have direct impact on emissions like NOx and soot production during combustion process. Auto-ignition and flame stabilization of diesel combustion mainly depend on 
combustion model used in such simulations. In the past, skeletal mechanism of $n$-heptane has been commonly used [20-23]. However, n-heptane-based mechanisms contain only lighter hydrocarbons and do not represent the higher hydrocarbons that are present in diesel, which are in the range of $\mathrm{C}_{10}-\mathrm{C}_{25}$. Although reaction mechanisms involving larger hydrocarbons have been developed, based on ndecane [24], n-dodecane [25] and n-hexadecane [26], these mechanisms are not fully validated or are too large to be incorporated in 3D CFD simulations. The present study adopted a validated n-

dodecane mechanism consisting of chemistry up to $\mathrm{C}_{12}$. In addition, thermo-physical properties (density, viscosity, surface tension) also show good agreement for $\mathrm{n}$-dodecane as surrogate for diesel fuels. Therefore, n-dodecane can better represent the diesel fuel as a surrogate [27-35], and will be adopted here as a representative fuel to describe diesel combustion. As for the reliable reaction mechanisms for butanol, the mechanism by Wang et al [36] is based on nheptane/butanol/PAH mechanism and has been used by Chen et al [37] in studying in-cylinder combustion for butanol/diesel blends.

As noted before, $n$-dodecane is a superior surrogate fuel of diesel as compared to n-heptane. To the authors' knowledge, no mechanism for mixtures of $\mathrm{n}$-dodecane/butanol is found in literature. Hence, a new mechanism representing combustion of $\mathrm{n}$-dodecane/butanol blends was developed. This new mechanism was validated for the limiting cases of $100 \%$ n-butanol and $100 \%$ n-dodecane by comparing the predicted ignition delay (ID) with ID reported in open literature for a 0 -D homogenous reactor model. Ignition delay for various blend ratios of n-butanol in n-dodecane was determined using the KAUST IQT (KR-IQT) experimental setup. Finally, CFD simulations were performed using this new mechanism and simulated ID was compared with the ID determined from the IQT experiments.

\section{Model Development}

\section{Dodecane/n-butanol reaction mechanism}

A 203 species and 709 reaction mechanism to describe the chemistry of $n$-dodecane/n-butanol mixtures was developed with by combining n-dodecane [25] and n-butanol [3] mechanisms. Luo et al [25] developed a 106 species and 420 reactions skeletal mechanism for ndodecane from 2755 species, and 11,173 reactions by using direct relation graph with expert knowledge (DRGX) and sensitivity analysis. The skeletal model was shown to have good prediction of ignition delay and flame lift-off length under high temperature condition [25]. The model also captured the transient flame development, and was validated against experimental data for shocktube ignition delay, JSR speciation, laminar flame speed and counter flow flame temperature in [25]. The alcohol mechanism was developed for all C1-C5 ethanol and butanol isomers [3]. This mechanism was developed using experimental data from shock tube, rapid compression machine, jet-stirred and flow reactors and laminar flame in [3].

In order to validate the new mechanism, ignition delay for the limiting cases of $100 \%$ dodecane and $100 \% \mathrm{n}$-butanol was modelled using 0-D homogenous reactor model across a range of initial temperature, pressure, and equivalence ratio conditions of relevance to diesel engine combustion.

Figure 1 shows the comparisons of n-butanol at stoichiometric condition and pressures of 10, 20, 40 and 80 bar using homogeneous reactor model. The new combined mechanism shows good agreement with the detailed alcohol mechanism for all the simulated pressures and temperature ranges of $600 \mathrm{~K}$ to $1200 \mathrm{~K}$ at $50 \mathrm{~K}$ increments. Figure 2 shows the ignition delay time data for $\mathrm{n}$-dodecane at equivalence ratios of 0.5 (a,b, and c) and 2.0 (d, e, and f) and pressures of 1,10 and 100 bar. The result shows good agreement at higher temperature conditions although there are some deviations at lower temperatures. To match the ignition delay from the combined mechanism with the detailed alcohol mechanism for the limiting case of $100 \%$ n-butanol (or $0 \%$ n-dodecane), the original rate constant of the following reaction [3] was divided by factor of 6 .

$$
\mathrm{C}_{4} \mathrm{H}_{8} \mathrm{OH}-4 \mathrm{O}_{2} \Leftrightarrow \mathrm{C}_{4} \mathrm{H}_{7} \mathrm{OH}-40 \mathrm{OH}-1
$$

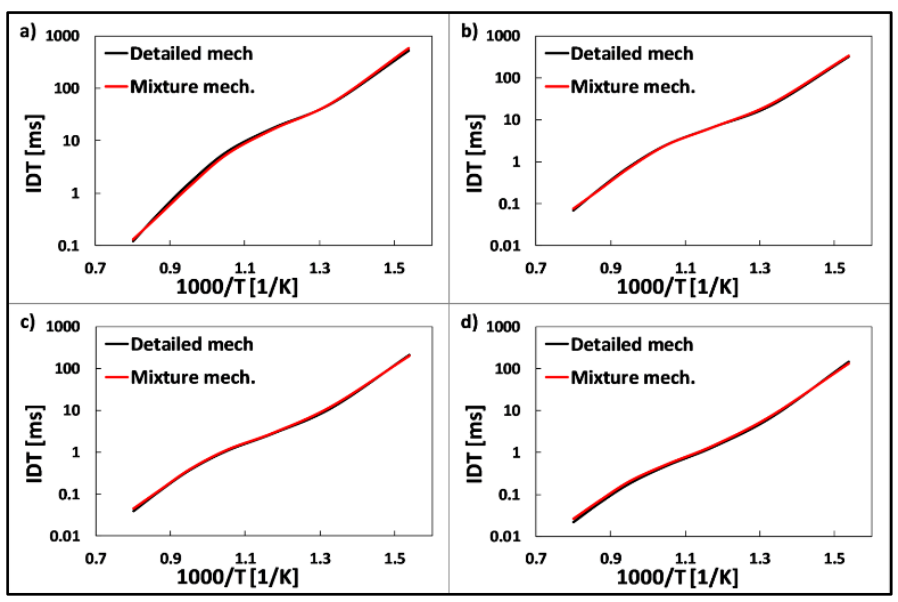

Figure 1. Comparison of detailed and mixture mechanism for ignition delay time at stoichiometric conditions of n-butanol at a) 10, b) 20, c) 40 and d) 80 bar.
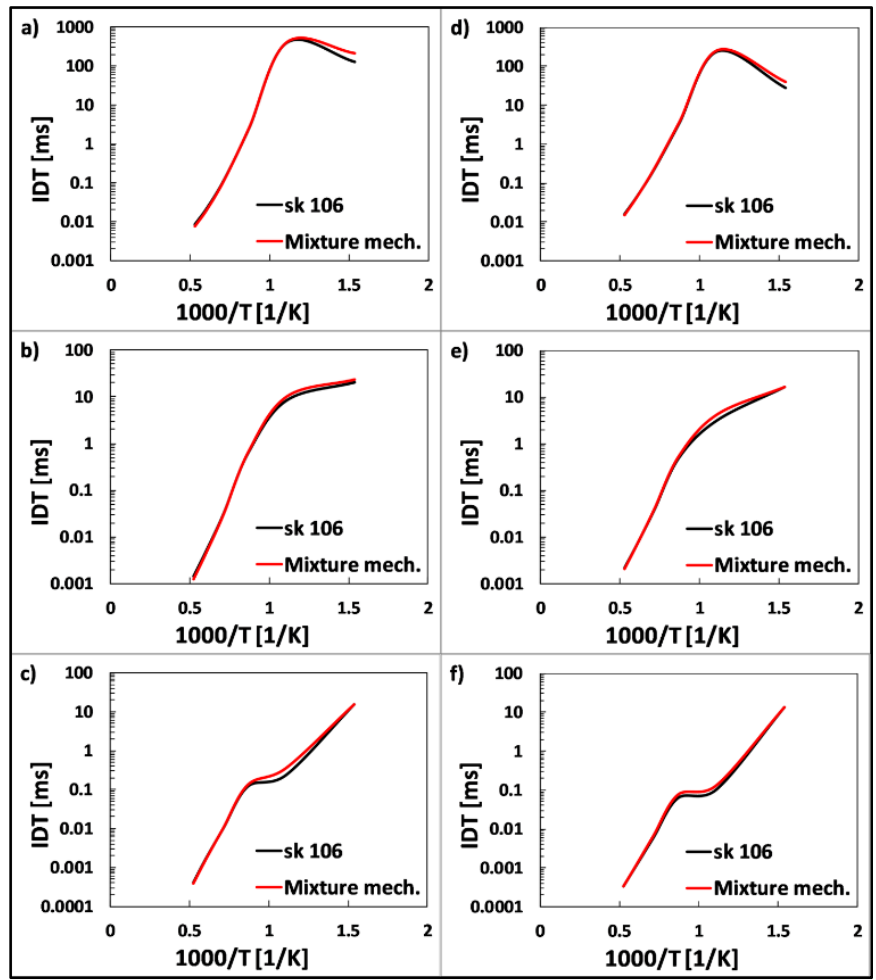

Page 2 of 8 
Figure 2. Comparison of skeletal and mixture mechanism for ignition delay time at a) $\mathrm{P}=1$ bar, $\varphi=0.5, \mathrm{~b}) \mathrm{P}=10$ bar, $\varphi=0.5$, c) $\mathrm{P}=100$ bar, $\varphi=0.5$ and d) $\mathrm{P}=1$ bar, $\varphi=2.0$, e) $\mathrm{P}=10$ bar, $\varphi=2.0$, f) $\mathrm{P}=100$ bar, $\varphi=2.0$ for $\mathrm{n}$ dodecane.

\section{Experimental Setup and Results}

Table 1 shows the experimental test matrix done in the KR-IQT. The temperature and pressure was selected in order to maintain a constant global equivalence ratio. The fuel properties of $n$-dodecane and butanol are shown in Table 2 .

Table 1. Experimental Test Matrix

\begin{tabular}{|c|c|c|c|}
\hline \multicolumn{3}{|c|}{ Experimental Test Matrix } \\
\hline Temperature (K) & \multicolumn{3}{c|}{$703-843$} \\
\hline Equivalence Ratio ( $\phi)$ & 0.85 & 0.85 & 1.5 \\
\hline Chamber Pressure (bar) & 21 & 18 & 10 \\
\hline n-dodecane & $\checkmark$ & $\checkmark$ & $\checkmark$ \\
\hline n-DB5 & $\checkmark$ & $\checkmark$ & $\checkmark$ \\
\hline n-DB10 & $\checkmark$ & $\checkmark$ & $\checkmark$ \\
\hline n-DB20 & $\checkmark$ & $\checkmark$ & $\checkmark$ \\
\hline Equivalence Ratio ( $\phi)$ & 0.7 & 0.7 & 1.5 \\
\hline n-Butanol & $\checkmark$ & $\checkmark$ & $\checkmark$ \\
\hline
\end{tabular}

Table 2. Fuel properties [40]

\begin{tabular}{|l|l|l|}
\hline Properties & n-dodecane & n-butanol \\
\hline Density $\left(\mathrm{kg} / \mathrm{m}^{3}\right)$ at $20^{\circ} \mathrm{C}$ & 749.5 & 810 \\
\hline Viscosity $\left(\mathrm{mm}^{2} / \mathrm{s}\right)$ at $40^{\circ} \mathrm{C}$ & 1.34 & 2.63 \\
\hline Boiling Point $\left({ }^{\circ} \mathrm{C}\right)$ & 216.3 & 117.7 \\
\hline Flash point $\left({ }^{\circ} \mathrm{C}\right)$ & 83 & 98 \\
\hline Auto-ignition temperature $\left({ }^{\circ} \mathrm{C}\right)$ & 203 & 343 \\
\hline Calorific value $(\mathrm{MJ} / \mathrm{kg})$ & 44.147 & 33.1 \\
\hline Surface tension $(\mathrm{m} / \mathrm{Nm})$ at $20^{\circ} \mathrm{C}$ & 25.35 & 24.2 \\
\hline
\end{tabular}

Figure 3(a) shows the schematic of the KR-IQT which is a constant volume chamber $(0.213 \pm 0.002 \mathrm{~L})$. A single hole S-type Pintle nozzle (ND-DN12SD12) with outer diameter of $1.1 \mathrm{~mm}$ and inner diameter of $0.8 \mathrm{~mm}$ was used to inject liquid fuel in the IQT (Fig. 3 (b)). The experimental parameters, such as initial temperature, pressure, mass of fuel injected are well controlled. The mass injected was calculated by averaging 20 injection injected in a measuring tube. The IQT is heated to the required temperature with cartridge type heaters. A piezoelectric pressure traducer (Kistler $601 \mathrm{~B} 1$ ) was used to measure pressure during the IQT experiment. A pneumatically driven mechanical pump was used to inject the liquid fuel at $18.14 \pm 0.54 \mathrm{Mpa}$. The injection duration is approximately $2 \mathrm{~ms}$. An Omega K-type thermocouple was used to measure the temperature inside the IQT. Ignition delay was estimated from the IQT chamber pressure and proximity sensor that measures the needle lift. The ignition delay time is defined as the time difference between the rise in chamber pressure (start of ignition) and opening of the fuel injector (start of injection). More details on the definitions of start of ignition and injection are available in [32][33][38]. The temperature is fairly uniform in the main portion of IQT because the nine heaters were equally spaced along the circumferential direction and chamber is well insulted with a thick layer of insulation.

Page 3 of 8
The experiments were conducted for blends of 5\%,10\% and 20\% (by vol.) of n-butanol in $n$-dodecane. The global equivalence ratio was maintained at 0.85 while chamber pressure was maintained at 21 and 18 bar and a global equivalence ratio of 1.5 was achieved at 10 bar. The ignition delay was measured within temperature range from 703 to $843 \mathrm{~K}$. Figure 4 shows that butanol has high ignition delay and by increasing the $n$-butanol percentage in the blend, ignition delay increased gradually for all the pressures.

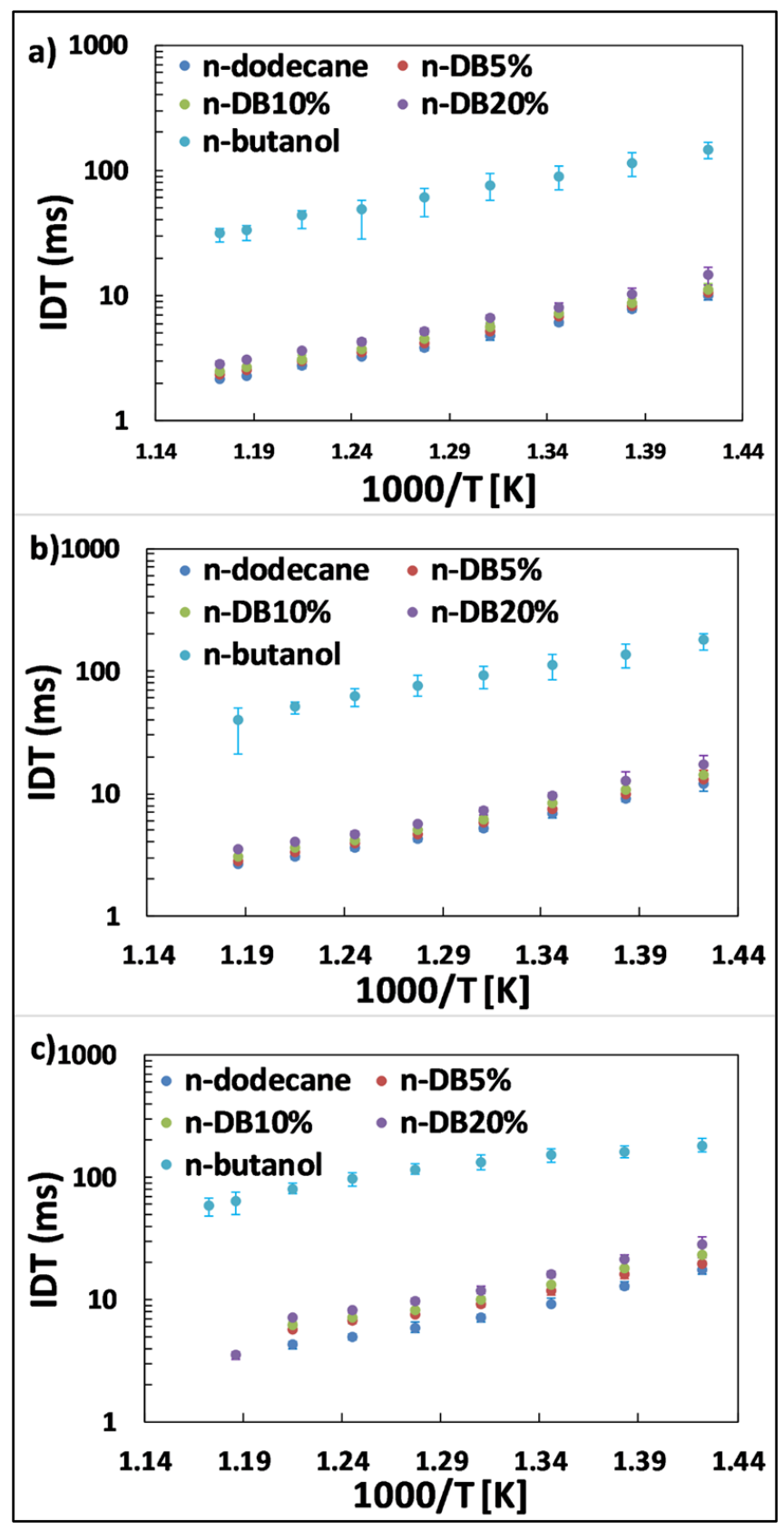

Figure 4. Experimental total ignition delay time for various fuel composition at $\varphi=0.85$ and pressure a) 21, b) 18 and c) $10 \mathrm{bar}$ from IQT

\section{Computational Setup and Results}

Commercially available computational fluid dynamic (CFD) solver, CONVERGE, was used to simulate the combustion process in IQT. Unsteady conservation equations for mass, momentum, species and 
energy were solved. For the turbulence closure, the standard renormalization group (RNG) k-epsilon model was used, in which the turbulent eddy viscosity is determined by

$$
\mu_{t}=\mu+C_{\mu} \rho \frac{k^{2}}{\varepsilon}
$$

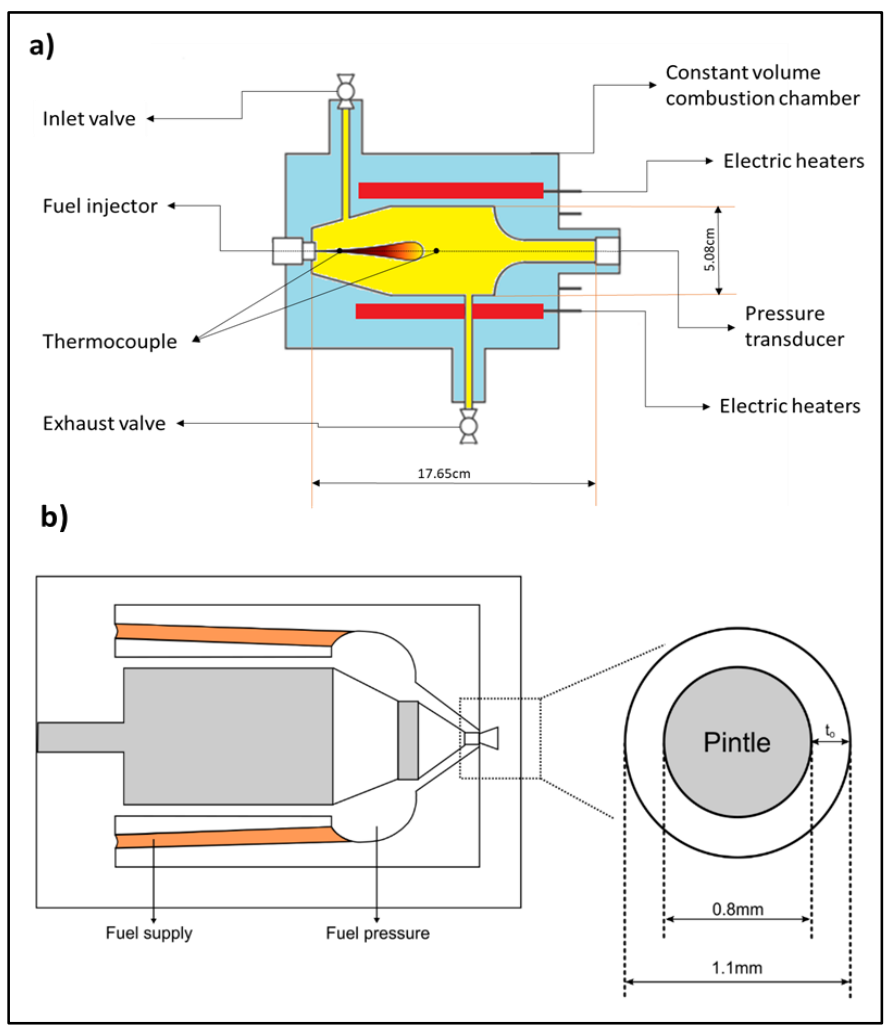

Figure 3. a) Schematic of IQT test constant volume combustion chamber (CVCC) [33], b) Schematic of IQT Injector body

where $C_{\mu}$ is a model constant, $k$ and $\varepsilon$ is turbulent kinetic energy and turbulent dissipation.

A Lagrangian approach was used to determine the spray droplet trajectory and the gas phase was modelled by solving the NavierStokes equation. As the droplets are injected at high velocity, there will be chances of collision and coalescence of the droplets. The widely used O'Rourke [39] collision and coalescence model was employed in the present study. The collision frequency of a collector drop with all the droplets is given by,

$$
V_{\text {coll }}=\frac{N_{2} \pi\left(r_{1}+r_{2}\right)^{2} V_{12}}{\Upsilon}
$$

where $N_{2}$ is the number of drops in the droplet parcel, $V_{12}=\mid v_{i 1}-$ $v_{i 12} \mid$ is the relative velocity between the collector and droplet parcel, $r_{1}$ and $r_{2}$ are the radii of the collector and droplet respectively, $\Upsilon$ is the volume of fluid-phase cell that includes the two parcels.
Rossin-Rammler distribution was prescribed as the initial droplet size distribution. A liquid blob was injected with a diameter equal to that of the injector nozzle hence the standard Kelvin-Helmholtz/RayleighTaylor (KH-RT) model was used to simulate secondary droplet brake-up and the constant used in simulations are shown in Table 3. The intact core or breakup length $L_{b}$ is given by

$$
L_{b}=C_{b l} \sqrt{\frac{\rho_{l}}{\rho_{g}}} d_{o}
$$

Where $d_{o}$ is nozzle exit diameter, $\rho_{l}$ and $\rho_{g}$ is the density of liquid droplets and gas phase. It is assumed that the $\mathrm{KH}$ instabilities are present within the breakup length $L_{b}$, but both instabilities are activated beyond breakup length. In such case, the code first checks for RT instabilities for the breakup, or else $\mathrm{KH}$ instabilities are responsible for droplet breakup. The n-dodecane and n-butanol mixture combustion mechanism in conjunction with the SAGE multizone model was used as the combustion submodel. To speed-up the computation of the reaction terms, CONVERGE create the Jacobian matrix which is calculated by CVODES (solves initial value problems for ordinary differential equation (ODE) system). Details of the above mentioned models can be found from the [39].

\section{Table 3. KH-RT Model Constants Matrix}

\begin{tabular}{|l|l|}
\hline KH-RT Model Constants & Constant Values \\
\hline KH Breakup model size constant $\left(\mathrm{B}_{0}\right)$ & 0.61 \\
\hline KH Breakup model velocity constant $\left(\mathrm{C}_{1}\right)$ & 0.188 \\
\hline KH Breakup model time constant $\left(\mathrm{B}_{1}\right)$ & 7.0 \\
\hline RT model time constant $\left(\mathrm{C}_{\tau}\right)$ & 1.0 \\
\hline RT model size constant $\left(\mathrm{C}_{\mathrm{RT}}\right)$ & 0.1 \\
\hline
\end{tabular}

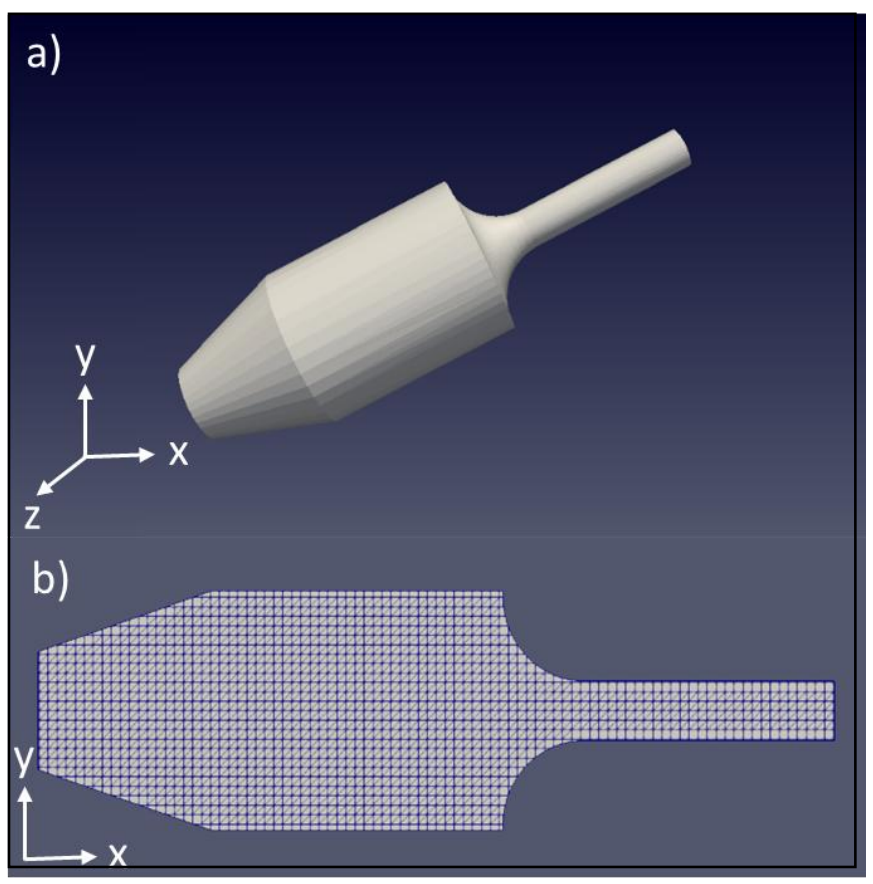

Figure 5. a) IQT geometry used in CONVERGE simulations, b) Mesh of IQT. 
A grid convergence study was done and the summary of this study is given in Table 4. Ignition delay estimated from simulations for three difference grid sizes for three different temperatures was used to determine the optimum grid for these simulations. As shown in Table 4 , the estimated ignition delay does not change significantly when the grid element size is reduced for $703 \mathrm{~K}$ and $743 \mathrm{~K}$. On the other hand, the ignition delay changes by approximately $9 \%$ when the grid element size is reduced from $1 \mathrm{~mm}$ to $0.5 \mathrm{~mm}$ for $843 \mathrm{~K}$. However, when the grid size is further reduced to $0.25 \mathrm{~mm}$, there is only marginal change in the predicted ignition delay value but computational time for $0.25 \mathrm{~mm}$ mesh was considerably higher than $0.5 \mathrm{~mm}$ mesh hence $0.5 \mathrm{~mm}$ mesh was used for all the subsequent simulations in this study. The simulations were able to reproduce the experiments which indicates the fidelity of the modelling approach adapted for the study.

Figure 6 shows the time history of the chamber pressure based on the experimental measurements and simulation. The ignition delay (ID) time in was determined from the start of injection to the time at which the pressure rise becomes maximum.

Table 4. Grid Test Matrix

\begin{tabular}{|l|c|c|c|}
\hline Property & \multicolumn{3}{|c|}{ CFD ID (ms)/ Mesh size } \\
\hline Temperature (K) & $1 \mathrm{~mm}$ & $0.5 \mathrm{~mm}$ & $0.25 \mathrm{~mm}$ \\
\hline 703 & 14.3 & 14.2 & 13.8 \\
\hline 743 & 4.11 & 4.10 & 4.02 \\
\hline 843 & 4.02 & 3.64 & 3.62 \\
\hline
\end{tabular}

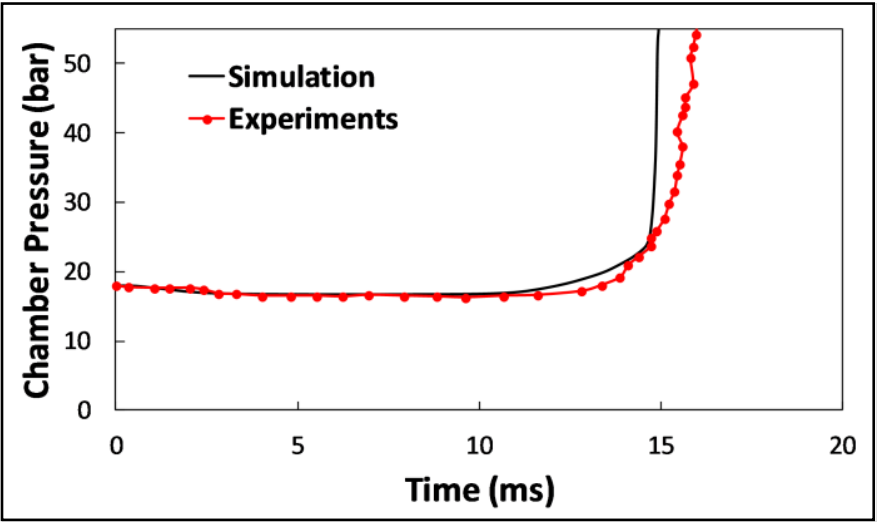

Figure 6. Experimental and simulated pressure traces for IDT for n-DB20 at 18bar, 703K.

Figures 7 and 8 show the ID obtained from the CFD simulations and are plotted along with the IQT experiments. The simulations were performed for three different temperatures of $703 \mathrm{~K}, 743 \mathrm{~K}$ and 843 $\mathrm{K}$ and two different pressures of 18 and 21 bar. It is seen that the numerical simulations over-predict the ID for dodecane when the temperature is $703 \mathrm{~K}$ and $843 \mathrm{~K}$ for both the pressures. However, there is a better agreement at $743 \mathrm{~K}$. However, when butanol is blended with dodecane, the ID agreement improves significantly. The ID prediction for $743 \mathrm{~K}$ and $843 \mathrm{~K}$ is in close agreement with the experimental data for both the pressures and all blends. The deviation is larger when the temperature is $703 \mathrm{~K}$ and pressure of 21 bar. However, when the pressure is reduced to $18 \mathrm{bar}$, the ID prediction at $703 \mathrm{~K}$ improves and is in much closer agreement with the experimental data.

Page 5 of 8
Figure 9 shows the temperature and equivalence ratio distribution for all blends at $\mathrm{t}=3$ and $5 \mathrm{~ms}$. It can be inferred that with increase of butanol percentage the homogeneity of the mixture increases. This is due to the longer ignition delay times which provides more time for fuel and air to mix. The ignition location varies inside the chamber depending on the percentage of butanol. The PDF homogeneity of the mixture at time of ignition is shown in Fig. 10. Clearly, for pure butanol the homogeneity is higher and reduces with decrease of butanol percentage in the blend. This can be useful in partially premixed compression ignition (PPCI) engines. With effective exhaust gas recirculation (EGR) and PPC the best trade-off between emissions and efficiency can be achieved [41]. As n-DB10 and nDB20 shows higher ID hence it can be use used in PPCI engines in ordered to reduce emissions. The PPC have substantial advantages towards liquid fuels by tolerating the injection strategy than the autoignition properties of fuel.

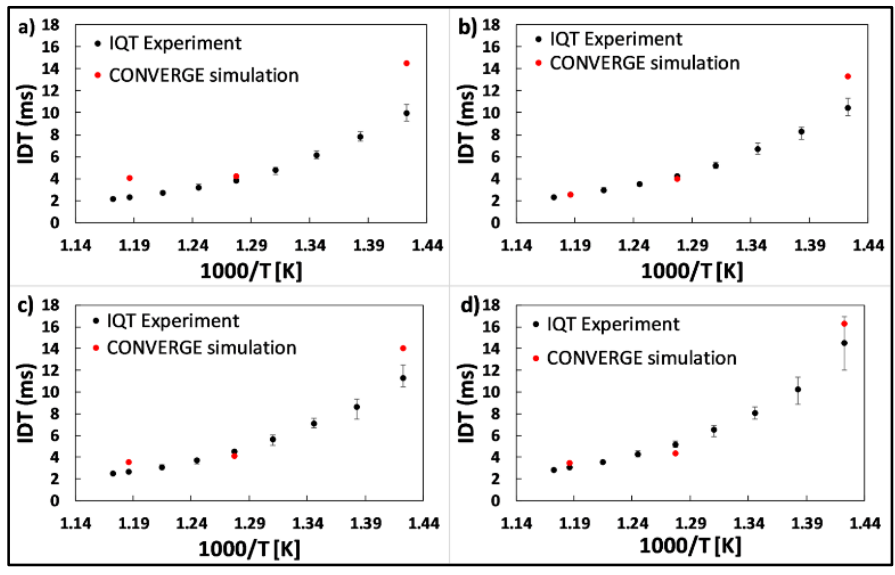

Figure 7. Comparison of IQT experimental and CONVERGE ignition delay at chamber pressure 21 bar for a) n-dodecane, b) n-DB5\%, c) n-DB10\% and d) $\mathrm{n}-\mathrm{DB} 20 \%$ at equivalence ratio of 0.85 .
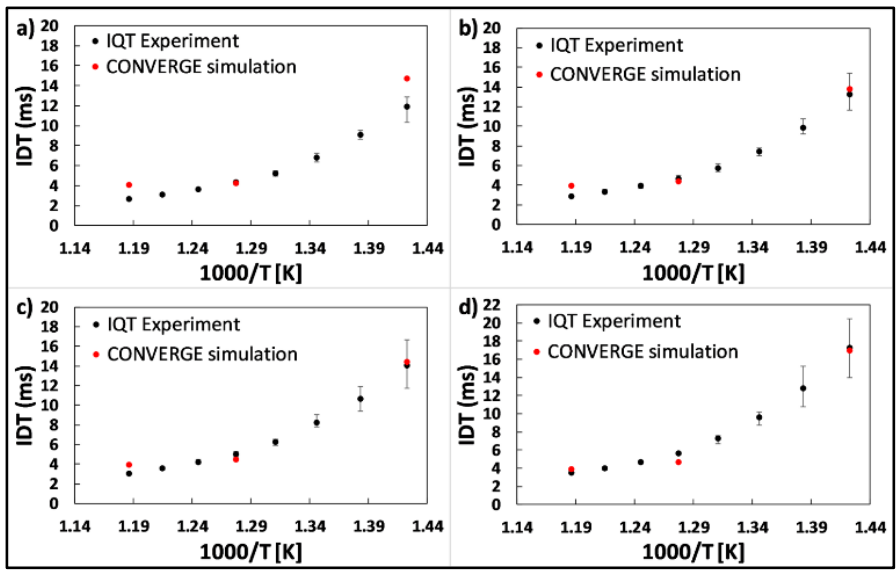

Figure 8. Comparison of IQT experimental and CONVERGE ignition delay at chamber pressure 18 bar for for a) n-dodecane, b) n-DB5\%, c) n-DB10\% and d) $\mathrm{n}-\mathrm{DB} 20 \%$ at equivalence ratio of 0.85 . 

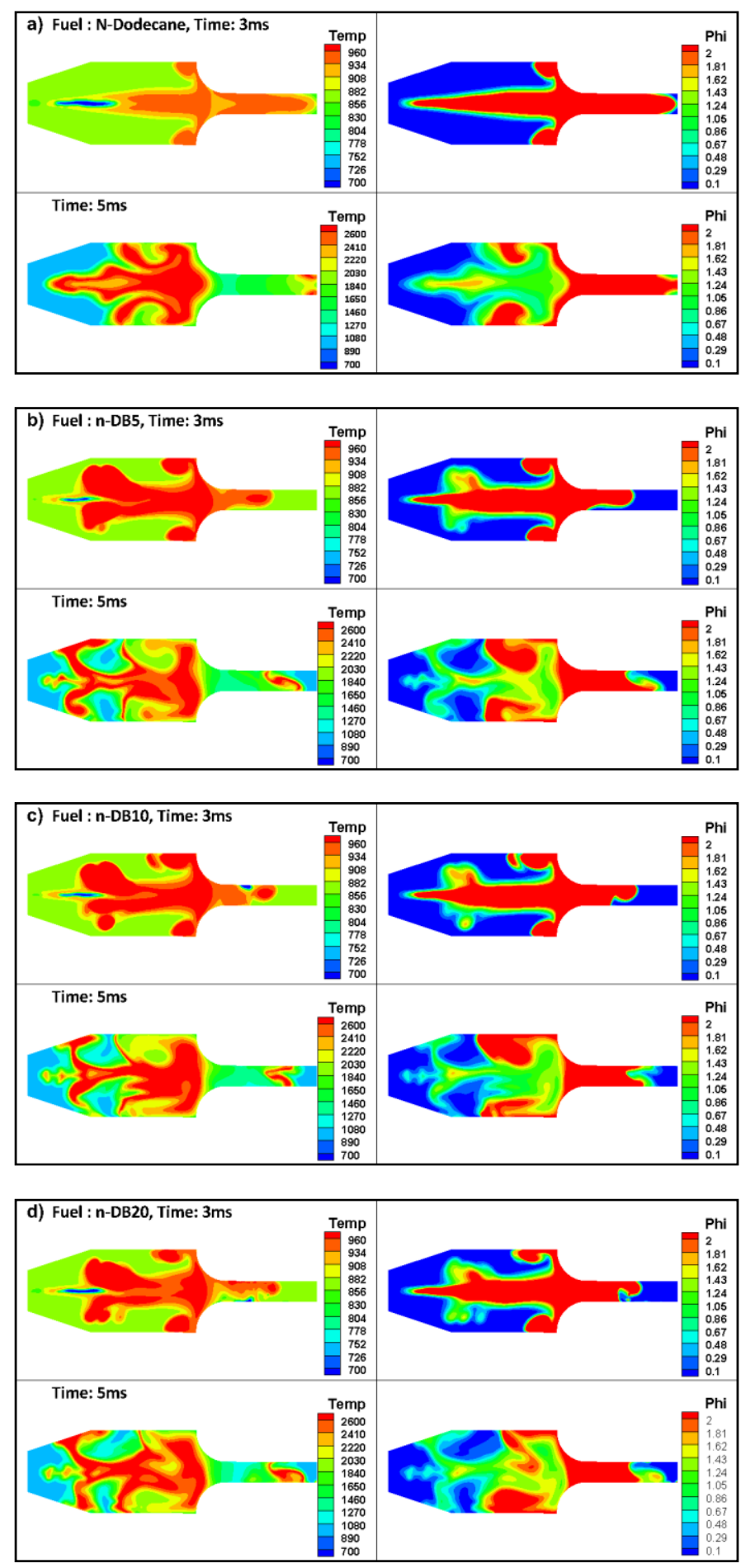

Figure 9. CFD results of IQT with temperature $(\mathrm{K})$ and equivalence ratio contours are shown at chamber pressure of 21 bar and temperature of $843 \mathrm{~K}$ at time of ignition for a) n-dodecane, b) n-DB-5, c) n-DB-10 and d) n-DB-20 respectively

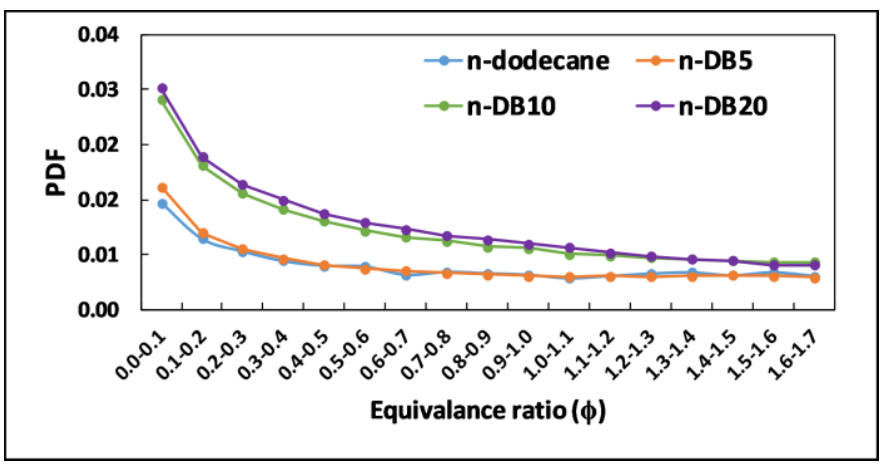

Figure 10. PDF of equivalence ratio for different blends at time of ignition at pressure of 21 bar and at temperature $843 \mathrm{~K}$.

The equivalence ratio distribution one time step before ignition is investigated to further understand the previous results. Pure ndodecane has lowest ignition delay time and is highly stratified (see Fig. 10), whereas, as the butanol percentage is increased, the mixture is homogeneously mixed and the PDF of stratification reduces. Clearly the mixture is leaner when the butanol percentage is increased which can be seen from the increased value of PDF at lean equivalence ratios.

\section{Conclusion}

A new mechanism of n-dodecane/butanol blend is developed using DRG-X method and validated with IQT experiments in the study. The new mechanism was developed by combining an existing dodecane skeletal and an alcohol mechanism from literature. This mechanism was validated by first comparing the ignition delay predicted for pure n-dodecane and n-butanol with the ignition delay predicted by their respective detailed mechanism. Ignition delay for dodecane/butanol blends were then experimentally determined using IQT and the corresponding CFD simulations were performed using the new mixture mechanism. The predicted ignition delay is in good agreement with the experiments. The longer ignition delay enhances the homogeneity of the chamber. From the above results it can be concluded that the developed mechanism can be effectively used in diesel engine CFD simulations.

\section{References}

1. http://mnre.gov.in/file-manager/UserFiles/biofuel policy.pdf

2. http://www.biodieseltechnologiesindia.com

3. Sarathy, S. Mani, et al. "Alcohol combustion chemistry." Progress in energy and Combustion Science 44 (2014): 40-102.

4. Z. Chen, Z. Wu, J. Liu, and C. Lee, "Combustion and emissions characteristics of high n-butanol/diesel ratio blend in a heavyduty diesel engine and EGR impact," Energy Convers. Manag., vol. 78, pp. 787-795, 2014.

5. X. Gu, G. Li, X. Jiang, Z. Huang, and C.f. Lee, "Experimental study on the performance of and emissions from a low-speed light-duty diesel engine fueled with n-butanol-diesel and isobutanol-diesel blends," Proc. Inst. Mech. Eng. Part D J. Automob. Eng., vol. 227, no. 2, pp. 261-271, 2012.

6. Chao Jin, Mingfa Yao, Haifeng Liu, Chia-fon F. Lee, Jing Ji, "Progress in the production and application of n-butanol as a biofuel", In Renewable and Sustainable Energy Reviews, Volume 15, Issue 8, Pages 4080-4106, 2011. 
7. D. C. Rakopoulos, "Combustion and emissions of cottonseed oil and its bio-diesel in blends with either n-butanol or diethyl ether in HSDI diesel engine," Fuel, vol. 105, pp. 603-613, 2013.

8. D. C. Rakopoulos, C. D. Rakopoulos, E. G. Giakoumis, A. M. Dimaratos, and D. C. Kyritsis, "Effects of butanol-diesel fuel blends on the performance and emissions of a high-speed di diesel engine," Energy Convers. Manag., vol. 51, no. 10, pp. 1989-1997, 2010.

9. O.Dogan, "The influence of n-butanol/diesel fuel blends utilization on a small diesel engine performance and emissions," Fuel, vol. 90, no. 7, pp. 2467-2472, 2011.

10. M. I. Al- Hasan and M. Al- Momany, "The effect of iso- butanol- diesel blends on engine performance," Transport, vol. 23, no. 4, pp. 306-310, 2008.

11. X. Feng, M. Huo, C.-F. Lee, and H. Liu, "The Effects of EGR and Injection Timing on the Engine Combustion and Emission Performances Fueled by Butanol-Diesel Blends," SAE Int. J. Engines, vol. 5, no. 3, pp. 2011-01-2473, 2012.

12. B. Dhinesh, J. Isaac JoshuaRamesh Lalvani, M. Parthasarathy, K. Annamalai, An assessment on performance, emission and combustion characteristics of single cylinder diesel engine powered by Cymbopogon flexuosus biofuel, In Energy Conversion and Management, Volume 117, ISSN 0196-8904, Pages 466-474, 2016.

13. B. Dhinesh, R. Niruban Bharathi, J. Isaac JoshuaRamesh Lalvani, M. Parthasarathy, K. Annamalai, An experimental analysis on the influence of fuel borne additives on the single cylinder diesel engine powered by Cymbopogon flexuosus biofuel, In Journal of the Energy Institute, Volume 90, Issue 4, ISSN 1743-9671, Pages 634-645, 2017.

14. Badra, J. A., Sim, J., Elwardany, A., Jaasim, M., Viollet, Y., Chang, J., ... \& Im, H. G. (2016). Numerical simulations of hollow-cone injection and gasoline compression ignition combustion with naphtha fuels. Journal of Energy Resources Technology, 138(5), 052202.

15. Naser, N., Jaasim, M., Atef, N., Chung, S. H., Im, H. G., \& Sarathy, S. M. (2017). On the effects of fuel properties and injection timing in partially premixed compression ignition of low octane fuels. Fuel, 207, 373-388.

16. Atef, N., Badra, J., Jaasim, M., Im, H. G., \& Sarathy, S. M. (2018). Numerical investigation of injector geometry effects on fuel stratification in a GCI engine. Fuel, 214, 580-589.

17. An, Y., Jaasim, M., Vallinayagam, R., Vedharaj, S., Im, H. G., \& Johansson, B. (2018). Numerical simulation of combustion and soot under partially premixed combustion of low-octane gasoline. Fuel, 211, 420-431.

18. Perez, F. H., Vallinayagam, R., Vedharaj, S., Johansson, B., \& Im, H. (2017). Computational Study of Stratified Combustion in an Optical Diesel Engine (No. 2017-01-0573). SAE Technical Paper.

19. Pitsch, H., Barths, H., \& Peters, N. (1996). Three-dimensional modeling of NOx and soot formation in DI-diesel engines using detailed chemistry based on the interactive flamelet approach (No. 962057). SAE Technical Paper.

20. Wright, Y. M., Margari, O. N., Boulouchos, K., De Paola, G., \& Mastorakos, E. (2010). Experiments and simulations of $\mathrm{n}$ heptane spray auto-ignition in a closed combustion chamber at diesel engine conditions. Flow, turbulence and combustion, 84(1), 49-78.

21. Pitz, W. J., \& Mueller, C. J. (2011). Recent progress in the development of diesel surrogate fuels. Progress in Energy and Combustion Science, 37(3), 330-350.

22. Kolaitis, D. I., \& Founti, M. A. (2009). On the assumption of using n-heptane as a "surrogate fuel" for the description of the cool flame oxidation of diesel oil. Proceedings of the Combustion Institute, 32(2), 3197-3205.

23. Hamosfakidis, V., \& Reitz, R. D. (2003). Optimization of a hydrocarbon fuel ignition model for two single component surrogates of diesel fuel. Combustion and flame, 132(3), 433450.

24. Jahangirian, S., Dooley, S., Haas, F. M., \& Dryer, F. L. (2012). A detailed experimental and kinetic modeling study of n-decane oxidation at elevated pressures. Combustion and Flame, 159(1), 30-43.

25. Luo, Z., Som, S., Sarathy, S. M., Plomer, M., Pitz, W. J., Longman, D. E., \& Lu, T. (2014). Development and validation of an n-dodecane skeletal mechanism for spray combustion applications. Combustion theory and modelling, 18(2), 187-203.

26. Poon, H. M., Ng, H. K., Gan, S., Pang, K. M., \& Schramm, J. (2013). Evaluation and development of chemical kinetic mechanism reduction scheme for biodiesel and diesel fuel surrogates. SAE International Journal of Fuels and Lubricants, 6(2013-01-2630), 729-744.

27. D'Errico, Gianluca, et al. Reduced kinetic mechanisms for diesel spray combustion simulations. No. 2013-24-0014. SAE Technical Paper, 2013.

28. Som, Sibendu, et al. Comparison and standardization of numerical approaches for the prediction of non-reacting and reacting diesel sprays. No. 2012-01-1263. SAE Technical Paper, 2012.

29. Jangi, Mehdi, et al. Numerical simulation of the ECN spray A using multidimensional chemistry coordinate mapping: nDodecane diesel combustion. No. 2012-01-1660. SAE Technical Paper, 2012.

30. Pei, Yuanjiang, et al. Large eddy simulation of a reacting spray flame under diesel engine conditions. No. 2015-01-1844. SAE Technical Paper, 2015.

31. L. N. Allard et al., "Analysis of the Ignition Behaviour of the ASTM D-613 Primary Reference Fuels and Full Boiling Range Diesel Fuels in the Ignition Quality Tester ( IQT ) - Part III," SAE Tech. Pap., no. 1999-01-3591, 1999.

32. G. E. Bogin et al., "Numerical and experimental investigation of n-heptane autoignition in the ignition quality tester (IQT)," Energy and Fuels, vol. 25, no. 12, pp. 5562-5572, 2011.

33. N. Naser, S. Y. Yang, G. Kalghatgi, and S. H. Chung, "Relating the octane numbers of fuels to ignition delay times measured in an ignition quality tester (IQT)," Fuel, vol. 187, pp. 117-127, 2017.

34. G. E. Bogin, J. Luecke, M. A. Ratcliff, E. Osecky, and B. T. Zigler, "Effects of iso-octane/ethanol blend ratios on the observance of negative temperature coefficient behavior within the Ignition Quality Tester," Fuel, vol. 186, pp. 82-90, 2016.

35. Z. Zheng, T. Badawy, N. Henein, and E. Sattler, "Investigation of Physical and Chemical Delay Periods of Different Fuels in the Ignition Quality Tester," J. Eng. Gas Turbines Power, vol. 135, no. 6, pp. 61501-1, 2013.

36. Wang, H.; Reitz, R. D.; Yao, M.; Yang, B.; Jiao, Q.; Qiu, L., Development of an n-heptane-n-butanol-PAH mechanism and its application for combustion and soot prediction. Combust. Flame 2013, 160, (3), 504-519

37. Zheng Chen Zhenkuo Wu Jingping Liu Chiafon Lee Combustion and emissions characteristics of high nbutanol/diesel ratio blend in a heavy-duty diesel engine and EGR impact, Energy Conversion and Management, Volume 78, February 2014, Pages 787-795

38. S. Y. Yang, N. Naser, S. H. Chung, and J. Cha, "Effect of Temperature, Pressure and Equivalence Ratio on Ignition Delay in Ignition Quality Tester (IQT): Diesel, $\mathrm{n}$-Heptane, and iso - 
Octane Fuels under Low Temperature Conditions," SAE Int. J. Fuels Lubr., vol. 8, no. 3, pp. 2015-01-9074, 2015.

39. Richards, K., Senecal, P., Pomraning, E., "CONVERGE 2.2. 0 Theory Manual". Convergent Science Inc., Madison, WI (2013)

40. https://pubchem.ncbi.nlm.nih.gov/

41. Lewander, M., Ekholm, K., Johansson, B., Tunestål, P., Milovanovic, N., Keeler, N., ... \& Bergstrand, P. (2008). Investigation of the combustion characteristics with focus on partially premixed combustion in a heavy duty engine. $S A E$ International Journal of Fuels and Lubricants, 1(2008-011658), 1063-1074.

\section{Contact Information}

Dr. Mani Sarathy

Clean Combustion Research Center

King Abdullah University of Science and Technology (KAUST)

Thuwal, Saudi Arabia

mani.sarathy@kaust.edu.sa
Dr. Raja Banerjee

Department of Mechanical and Aerospace Engineering Indian institute of Technology Hyderabad

Kandi Campus, Sangareddy

India -502285

rajabanerjee@iith.ac.in

\section{Acknowledgments}

This work was funded by competitive research funding from King Abdullah University of Science and Technology (KAUST) under the Clean Combustion Research Center internship program in collaboration with IIT Hyderabad. We would like to express our gratitude to Research Scholar Mr. Eshan Singh, for his support in carrying out Experiments at KAUST. 